\title{
Morphochemical age-related changes in the nematode Caenorhabditis elegans: immunoperoxidase localization of cytokine- and growth factor-like molecules
}

\author{
A. Franchini, E. Peruzzi, E. Ottaviani \\ Department of Animal Biology, University of Modena and Reggio Emilia, Modena, Italy
}

(C)2003, European Journal of Histochemistry

Morphochemical age-related features in the hermaphrodite Caenorhabditis elegans are reported. The study of worms of different ages shows a gradual decline in response to the various histochemical reactions and a disorganization of the components of the gonad during ageing. Using an immunocytochemical procedure, we show for the first time the presence of immunoreactive IL-1 $\alpha$ and PDGF-AB molecules in neurons from young adult $C$. elegans. Moreover, TNF- $\alpha$ - and PDGF-AB-like molecules are also present in the secretory cells of the pharyngeal terminal bulb. The number of positive cells to anti-cytokine and anti-growth factor antibodies decreases in older worms, suggesting that these molecules may play an important role in worm ageing. The present investigation therefore supports the findings in the literature obtained with different approaches on the crucial role of the nervous and reproductive systems in the life span of $C$. elegans.

Key words: Caenorhabditis elegans, cytokines, growth factor, ageing, histochemistry, immunocytochemistry.

Correspondence: Professor Enzo Ottaviani, Dipartimento di Biologia Animale, via Campi 213/D, 41100 Modena, Italy. Phone: international +059.2055536. Fax: international

+059.2055548. E-mail: ottaviani.enzo@unimore.it

Paper accepted on October 4, 2002

European Journal of Histochemistry 2003; vol. 47 issue 1 [Jan-Mar]:75-80
V arious researchers have seen in the nematode Caenorhabditis elegans a useful model with which to address basic biological questions, as it is relatively simple both at anatomic and genomic level (Wood et al., 1988; Riddle et al., 1997). Adult worms are about $1 \mathrm{~mm}$ length, and each hermaphrodite organism is composed of 959 somatic cells and a haploid genome size of $8 \times 10^{7}$ nucleotide pairs (Wood et al., 1988). The structural form and the characteristic transparency of the animals have made genetic, differentiation and developmental experiments more common than histological studies. Indeed, the animal's small size, and the presence of a strong cuticle cause problems in classical section stainings, i.e. histochemistry and immunocytochemistry, and few such studies are available. C. elegans is also a suitable model that fulfils the basic criteria for ageing research (Gershon and Gershon, 2000, 2002).

In the present paper, we suggest a modification in the routine paraffin embedding procedure in order to obtain sections suitable for classical stainings allowing characterization of the histochemical modifications that occur during the ageing. Furthermore, to examine the role of cytokines and growth factors in $C$. elegans ageing, we have studied the presence of different cytokines and the platelet-derived growth factor (PDGF)-AB in the anterior part of the animal where the central nervous system is located. Recently, Wolkow et al. (2000) reported that an insulin-like signalling pathway in $C$. elegans neurons is sufficient to determine wild-type life-span.

\section{Materials and Methods}

\section{Culture of C. elegans}

C. elegans were grown on NGM (nematode growth medium) agar plates seeded with Escherichia coli strain $0 \mathrm{P} 50$ at a temperature of $20^{\circ} \mathrm{C}$, as described by Brenner (1974). NGM agar contains 
$1.7 \%$ agar powder dissolved in a solution containing $1 \mathrm{mM} \mathrm{CaCl} 2,1 \mathrm{mM} \mathrm{MgSO}{ }_{4}, 0.3 \% \mathrm{NaCl}_{1} 0.25 \%$ bactopeptone (Difco Lab., USA), $5 \mathrm{\mu g} \mathrm{mL}^{-1}$ cholesterol and $25 \mathrm{mM}$ potassium phosphate; $\mathrm{pH}$ 6.0.

\section{Preparation of synchronized populations of worms}

Adult worms laden with eggs were used to prepare synchronized populations of animals. These were lysed by alkaline hypochlorite treatment (Lewis and Fleming, 1995), and the isolated eggs were incubated in $\mathrm{M} 9$ buffer (20 mM KH $\mathrm{PO}_{4}, 40 \mathrm{mM} \mathrm{Na}_{2} \mathrm{HPO}_{4}$, $0.1 \mathrm{M} \mathrm{NaCl}, 1 \mathrm{mM} \mathrm{MgSO}_{4}$ ) (Brenner, 1974) at $20^{\circ} \mathrm{C}$ overnight. Hatched LI larvae were transferred to NGM agar plates seeded with E. coli and cultured at $20^{\circ} \mathrm{C}$. Young fertile adults present on the plates after 3 days, fertile adults present after 6 days, and old unfertile specimens present after 12 days were collected with a thin glass needle and transferred to freshly prepared Bouin's fixative and $4 \%$ p-formaldehyde in phosphate buffered saline solution. Samples were then cut into two parts to allow the fixative to penetrate. After $5 \mathrm{~h}$ of fixation, the cut worms were transferred to a $2 \mathrm{~mm}$ layer of $2 \%$ solidified agar water solution. These were then covered with $2 \%$ molten agar, and the worms embedded in agar gel were normally dehydrated in graded ethanols, cleared, embedded in paraffin wax and cut into $7 \mu \mathrm{m}$ transversal or longitudinal sections.

\section{Histological and histochemical study}

The following stains were carried out on sections: trichromic morphological stain (Gabe and Martoja-Pierson,1957); toluidine blue reaction for Nissl bodies; gallocyanin-chrome alum reaction (Bancroft and Stevens, 1996) for nucleic acids; PAS reaction, chrome alum haematoxylin-phloxine reaction (Bancroft and Stevens, 1996) for secretory material; Sudan black B reaction (Bancroft and Stevens, 1996) for lipids and Schmorl's method (Bancroft and Stevens, 1996) for lipofuscins.

\section{Immunohistochemical procedure}

The immunocytochemical procedure to determine the presence of cytokine- and growth factor-like molecules is described in detail elsewhere (Ottaviani et al., 1995). Briefly, slides were treated with the primary antibodies, goat anti-IL-1 $\alpha$, -IL-6 and -TNF- $\alpha$ (Santa Cruz Biotechonoloy, USA) and -PDGF-AB (Upstate Biotechonology, USA) polyclonal antibodies (pAb) (1:1000), overnight at $4^{\circ} \mathrm{C}$. The labelling sites were revealed using avidinbiotin-peroxidase complex (ABC). Negative controls were performed by substituting the primary antibodies with non-immune sera or by absorbing the anti-sera with homologous antigens. The experiments were repeated four times.

\section{Results}

The microscopic examination of stained longitudinal sections from young adult (fertile stage; 3 days after the LI stage) specimens of the hermaphrodite $C$. elegans showed four distinct pharyngeal regions in the anterior part of the animal: the procorpus, metacorpus, isthmus and terminal bulb (Figure 1). The latter two regions were surrounded by the central nervous system composed of small ganglia mainly organized anteriorly and posteriorly to the circumpharyngeal nerve ring, as reported by White et al. (1986). The small neuron cell bodies were easily distinguished after the histochemical reactions for $\mathrm{N}$ issl bodies, gallocyanin-chrome alum (Figure 1) and chrome alum haematoxylin-phloxine reaction. Moreover, the perikaria of neurons running anteriorly to the sensory organs in the animal's head (Figure 2), and the cytoplasm of secretory cells located in the terminal bulb wall were also positive (Figure 1). The histomorphological observation of the bilobed gonad sections revealed a yellow reacting cytoplasm of the syncytial ovary to trichromic staining that can be considered a lipid component (Figure 3), as also confirmed by Sudan black B staining. The ovary cytoplasm and that of developing oocytes inside the oviduct were intensely PAS positive and basophilic (Figure 4). Developing embryos were observed in uterus sections (Figure 3).

Fertile adult worms collected 6 days after the L1 stage did not show evident structural modifications with the exception of a swelling of pseudocoelomatic space (Figure 5), where droplets and heterogeneous inclusions stained with trichromic stain (Figure 6), Sudan black B and Schmorl reactions were accumulated. A decreased PAS positivity and basophilia of the mature oocytes was observed (Figure 7 ) in contrast to the immature cells (Figure 8) at gonad level.

The histological observation of sections from old unfertile ( 12 days after the Ll stage) worms showed a further swelling of pseudocoelomatic space, where droplets and heterogeneous inclusions were more conspicuous (Figure 9), and a disorgan- 

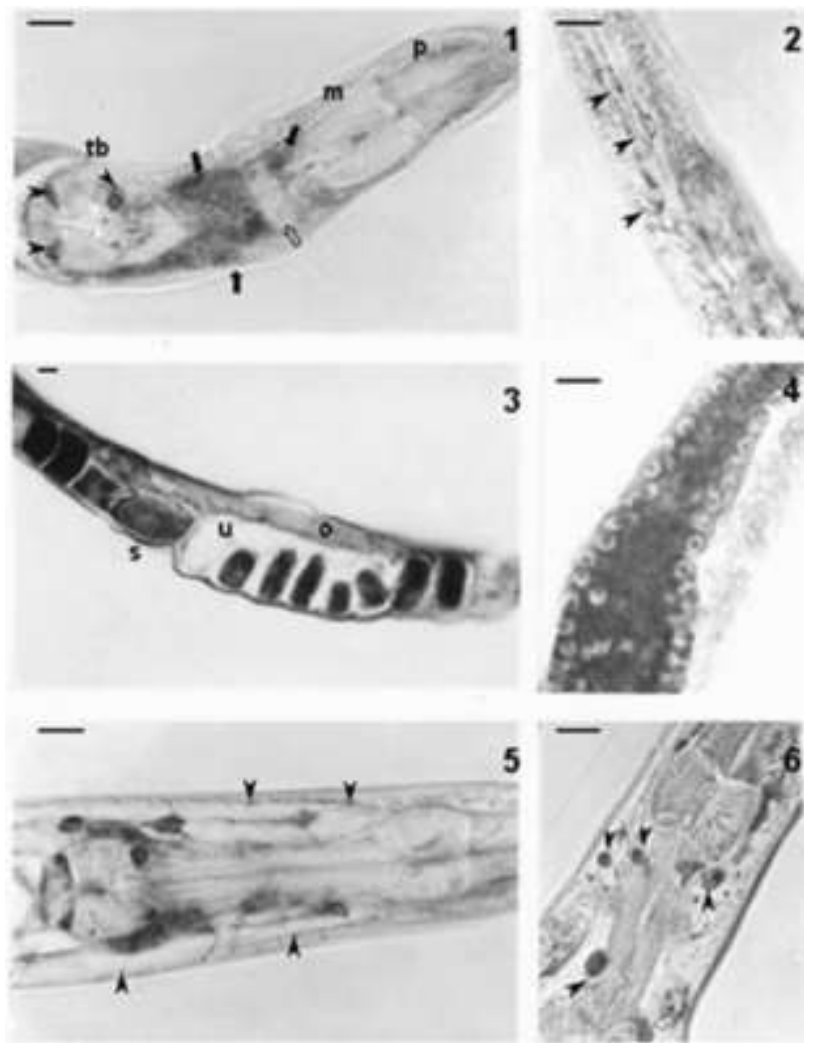

Figure 1. Longitudinal section of the anterior part of young adult worm ( 3 days after L1 stage) stained with gallocyanin-chrome alum reaction. Pharyngeal procorpus $(p)$, metacorpus $(m)$ and terminal bulb (tb); nerve ring (light arrow); ganglia of the central nervous system (black arrows); secretory cells of the terminal bulb (arrowheads). Bar=10 $\mu \mathrm{m}$. Figure 2. Longitudinal section at surface level of the anterior part of young adult worm stained with gallocyanin-chrome alum reaction. Positive cell bodies of neurons (arrowheads). Bar $=10 \mu \mathrm{m}$. Figure 3 . Longitudinal section of the gonad of young adult worm stained with trichromic stain. Ovary (o); spermatheca (s); uterus (u). Bar $=\mathbf{1 0} \mu \mathrm{m}$. Figure 4. Longitudinal section at the level of syncytial ovary of young adult worm stained with gallocyaninchrome alum reaction. Basophilic cytoplasm and nuclei at the periphery are shown. Bar $=\mathbf{1 0} \mu \mathrm{m}$. Figure $\mathbf{5}$. Longitudinal section of the anterior part of adult worm (6 days after L1 stage) stained with Nissl reaction. Note a swelling of pseudocoelomatic space (arrowheads). Bar $=10 \mu \mathrm{m}$. Figure 6. Longitudinal section of the anterior part of adult worm (6 days after L1 stage) stained with trichromic. Droplets in the pseudocoelomatic space are shown (arrowheads). Bar $=10 \mu \mathrm{m}$.

ization at gonad level. Syncytial ovarian nuclei were not regularly organized at the organ periphery (Figure 10) and the cytoplasm showed a decreased lipid storage component. The oocytes present inside the oviduct were less basophilic than those in young adult worms, and inclusions and vacuola were seen (Figure 11). Furthermore, the histochemical analysis of neuron cell bodies and pharyngeal secretory cell cytoplasm showed decreased basophilia (Figure 12).
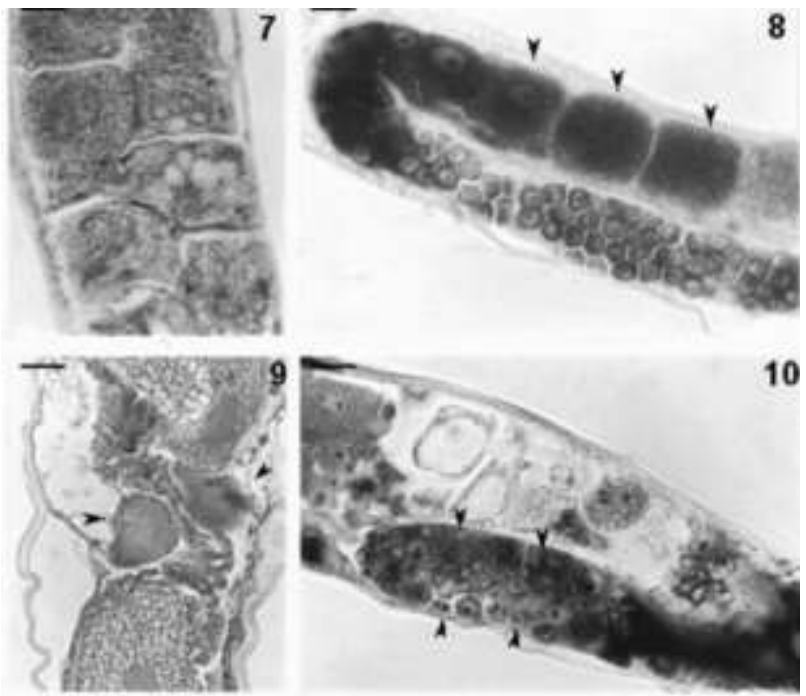

10

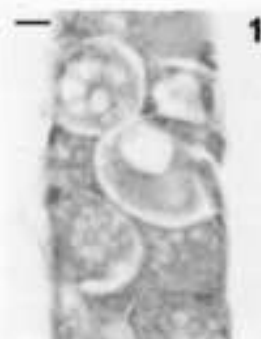

11

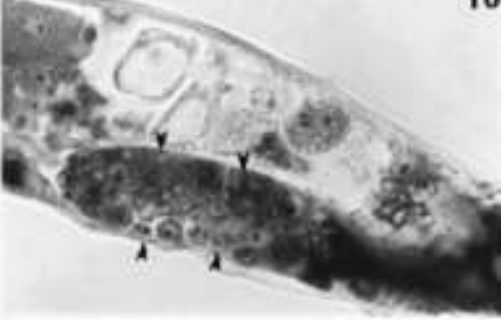

12

Figures 7, 8. Longitudinal section at gonad level of adult worm ( 6 days after L1 stage) stained with gallocyanin-chrome alum reaction. Note the decreased basophilia of the mature oocytes (Figure 7) in contrast to the immature ones (Fig. 8, arrowheads). Bar $=10 \mu \mathrm{m}$. Figure 9. Longitudinal section of adult worm (12 days after L1 stage) stained with Schmorl's reaction. Conspicuous heterogeneous inclusions and droplets are seen in the pseudocoelomatic space (arrowheads). Bar $=10 \mu \mathrm{m}$. Figure 10. Longitudinal section at the gonad level of adult worm (12 days after L1 stage) stained with trichromic. Note the ovary disorganization (arrowheads). Bar $=10 \mu \mathrm{m}$. Figure 11 . Longitudinal sections at the gonad level of adult worm (12 days after L1 stage) stained with gallocyanin-chrome alum reaction. Vacuola inside the oocytes are present. Bar $=10 \mu \mathrm{m}$. Figure 12. Longitudinal section of the anterior part of adult worm (12 days after L1 stage) stained with gallocyanin-chrome alum reaction. The basophilia of the cell bodies of neurons (arrows) and the secretory cells of pharyngeal terminal bulb (arrowheads) decreased. Bar $=10 \mu \mathrm{m}$.

With regards the immunocytochemical experiments, IL- $1 \alpha$, TNF- $\alpha$ and PDGF-AB immunoreactive molecules, but not IL-6, were found in both young adult (fertile stage; 3 days after the $L 1$ stage) and old adult (unfertile stage 12 days after the L1 stage) worms. In young adult animals, IL$1 \alpha$ was the most frequently expressed cytokine, and positive neurons were found in the anterior, lateral and retrovesicular ganglia (Figure 13). TNF- $\alpha$-like molecules were not found in neurons, but in four 

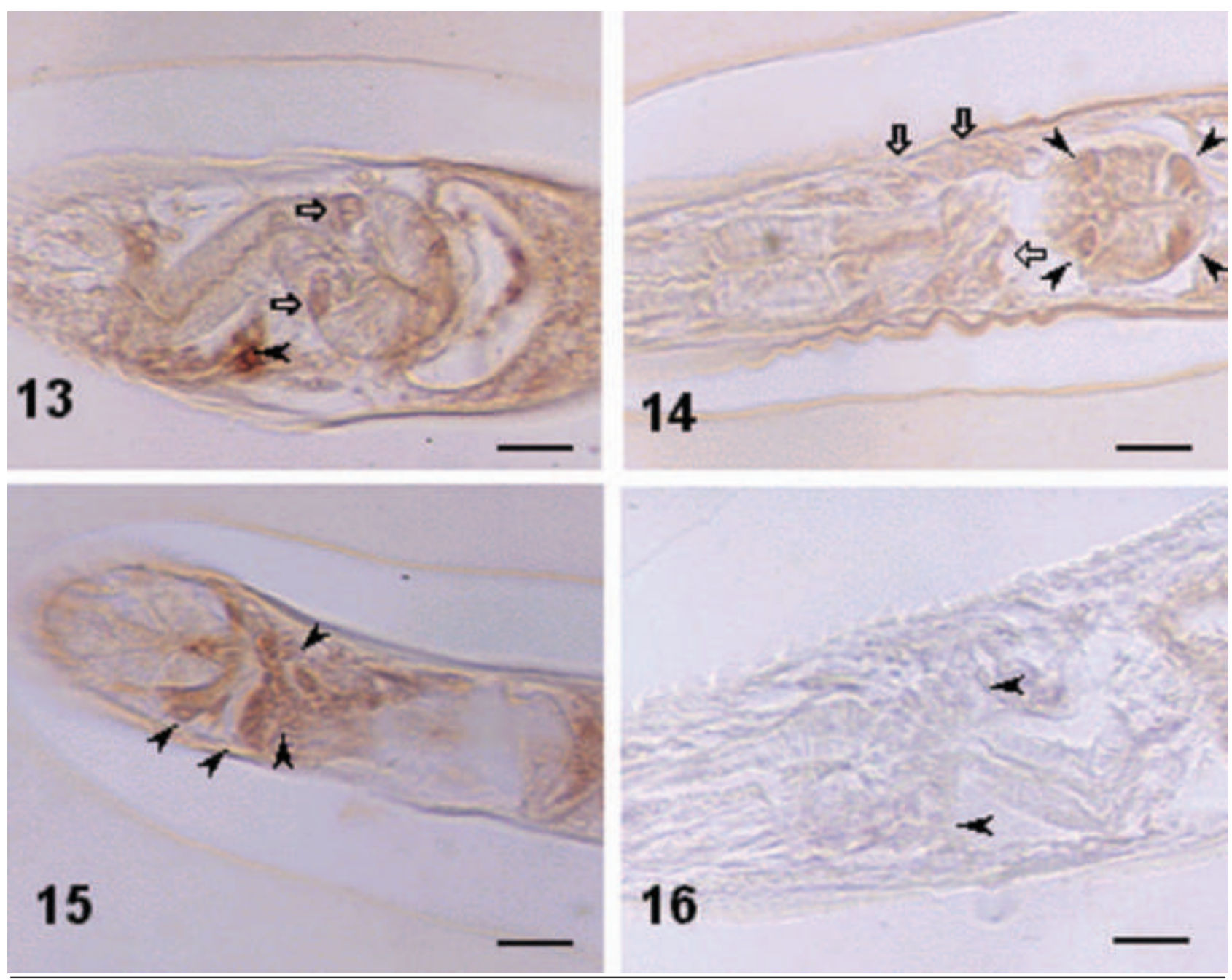

Figure 13. Longitudinal section of the anterior part of young adult worm (3 days after L1 stage) immunostained with anti-IL-1 $\alpha$ pAb. One positive neuron of the lateral ganglion (arrowhead) and negative secretory cells (light arrows) are shown. Bar $=10 \mu \mathrm{m}$. Figure 14. Longitudinal section of the anterior part of young adult worm immunostained with anti-TNF $\alpha$ pAb. Positive secretory cells (arrowheads) and negative neurons (light arrows) are shown. Bar $=\mathbf{1 0} \mu \mathrm{m}$. Figure 15. Longitudinal section of the anterior part of young adult worm immunostained with anti-PDGF-AB pAb. Immunoreactive neurons located in the pharyngeal isthmus are seen (arrowheads). Bar $=10 \mu \mathrm{m}$. Figure 16. Longitudinal section of the anterior part of adult worm (12 days after L1 stage) immunostained with anti-PDGF$A B$ pAb. Neurons located in the pharyngeal isthmus are (arrowheads) negative. Bar $=10 \mu \mathrm{m}$.

secretory cells of the pharyngeal terminal bulb (Figure 14). An intra-pharyngeal secretory cell and some neurons of the anterior and lateral ganglia were positive to anti-PDGF-AB pAb (Figure 15).

The study of the old animals revealed a general decrease in the number of cells positive to the antibodies tested. Only one immunoreactive cell to IL$1-\alpha$ was found in the lateral ganglion. The TNF- $\alpha$ positive secretory cells were less intense in the older animals, while a negative response was observed for PDGF-AB (Figure 16).

\section{Discussion}

The histomorphological features during ageing in the hermaphrodite $C$. elegans and the related modifications of cytokine- and growth factor-like molecules have been described. From this study, it emerges that the main modifications in the worm life are a general decreased response to the various histochemical reactions, and a gradual disorganization of the components of the gonads. Indeed, the basophilia of neurons, secretory cells and oocytes decreases, as does the lipid content present in ovary cytoplasm. Furthermore, droplets and heterogeneous inclusions positive to Schmorl and Sudan black $B$ reactions are accumulated in the pseudocoelomatic space and can be ascribed to lipofuscins. It is known that these pigments, found in various tissue and organs from invertebrates and verte- 
brates, are correlated to ageing and are termed age pigments (Ganter and Jollés, 1970; Durand and Desnoyers, 1980; Bonucci, 1981). The modifications in histochemical stainability of oocytes could be related to the decreased sperm contact that occurs with progress in the worm life. Indeed, old hermaphrodites that are depleted of sperms continue to produce oocytes even if they undergo partial maturation characterized by a lack of eggshell formation and the reduction in egg granule cytoplasm (Wood, 1988). Moreover, the reduced PAS positivity and basophilia of maturing oocytes present in the oviduct could be related to a decreased uptake of yolk protein synthesized outside the gonad and/or produced in situ (Kimble and Sharrock, 1983).

Evidence in the literature suggests an involvement of the nervous and reproductive systems in C. elegans senescence. In their review, Braeckman et al. (2001) claim that the nervous system controls the life span of the worm by integrating environmental stimuli and the internal signalling of the reproductive system. We have found morphochemical modification of the gonad, together with a decreased response in neurons of the central nervous system and secretory cells from old adult worms to histochemical reactions for $\mathrm{Niss}$ l bodies and chrome alum haematoxylin-phloxine. Moreover, immunoreactivity to anti-cytokine antibodies was reduced or disappeared, indicating an involvement of the neuroendocrine system in $C$. elegans ageing.

We and others have demonstrated the presence of cytokine- and growth factor-like molecules in several cell types from molluscs, insects and annelids (Ottaviani and Franceschi, 1997; Ottaviani et al., 1997, 2001). Moreover, mammalian cytokines and growth factors influence immunocyte cell shape, chemotaxis, phagocytosis and the wound repair process in invertebrates (Ottaviani and Franceschi, 1997; Ottaviani et al., 1997, 2001).

Various studies on cytokines indicate that they not only exert profound effects in target cells outside the immune system, but are also produced and utilized by cells of the nervous and endocrine systems (Geelhoed and Chernow, 1985), suggesting a role among the primary mediators of a variety of metabolic and neuroendocrine functions. In other words, cytokines are today considered critical molecules which link the immune and neuroendocrine systems (Imura et al., 1991), and in exerting a vari- ety of physiological functions in non-immune organs, they have become more than mere immune mediators. Growth factors are a large and diverse group of polypeptides which regulate several functions, such as cell proliferation, differentiation, chemotaxis, matrix production, wound healing and survival (Cross and Dexter, 1991; Clark, 1996; Heldin and Westermark, 1999). The role and continuous presence of cytokines and growth factors in basic biological phenomena from invertebrates to vertebrates suggest that these molecules have had a long evolutionary history.

In mammalian models, it has been found that cytokines and growth factors may contribute to age-associated changes. With regards the mechanisms of cytokine action in ageing, Franceschi et al. (1995) refer to "the 'yo-yo' cytokine network". Indeed, a complex remodelling of cytokines is characteristic of immunosenescence, where the production of these molecules declines or increases according to a well-defined, balanced network related to homeostatic changes during ageing. Moreover, the decreased expression and synthesis of PDGF- $\beta$-receptor in fibroblasts of subjects with Werner's syndrome, similar to that of fibroblasts in normal senescence, may be due to the decreased mitogenic response of the cells to PDGF (Mori et al., 1993). In this case, the decreased number of cells containing cytokine- and growth factor-like molecules reported here in old $C$. elegans indicates that these molecules may play an important role in worm ageing.

Wolkow and colleagues (2000) have reported the presence in the $C$. elegans nervous system of an insulin-like signalling that controls life span, metabolism and development. Mutations of the $C$. elegans daf-2 insulin/IGF-I-like receptor gene or phosphatidylinositol 3-OH kinase age-1 gene are able to extend the life span of adult worms two or three times by regulating the expression of a regulator of animal longevity the old- 1 gene which encodes a transmembrane tyrosine kinase (formerly TKR-1) (Kenyon et al., 1993; Morris et al., 1996; Kimura et al., 1997; Murakami and Johnson, 2001). The restoration of the functions of the daf- 2 and age- 1 genes show that the insulin-like signalling pathway in neurons alone is sufficient to determine a wildtype life span (Wolkow et al., 2000), suggesting that the nervous system acts as a central regulator of animal life span. 


\section{Acknowledgements}

The authors are grateful to Prof. R. Bertolani and Prof. A. Zullini who kindly supplied the strain of $C$. elegans. This work was supported by MIUR (Italy) grant to E.O.

\section{References}

Bancroft JD, Stevens A. Theory and practice of histological techniques. Churchill Levingstone, Edinburgh, 1996.

Bonucci E. Manuale di istochimica. Lombardo Editore, Roma, 1981.

Braeckman BP, Houthoofd K, Vanfleteren JR. Insulin-like signaling, metabolism, stress resistence and ageing in Caenorhabditis elegans. Mech Ageing Dev 2001;122:673-93.

Brenner S The genetics of Caenorhabditis elegans. Genetics 1974;77: 71-94.

Clark RAF. Wound repair. Overview and general considerations. In The molecular and cellular biology of wound repair. Clark RAF, Editor, Plenum Press: New York; 1996 p. 3-50.

Cross M, Dexter TM. Growth factors in development, transformation, and tumorigenesis. Cell 1991;64:271-80.

Durand G, Desnoyers F. Acides gras polyinsatures et vieillissement. Les lipofuscines: structure, origine, évolution. Ann Nutr Aliment 1999; 34:317-32.

Heldin $\mathrm{CH}$, Westermark B. Mechanism of action and in vivo role of platelet-derived growth factor. Physiol Rev 1999;79:1283-316.

Franceschi C, Monti D, Sansoni P, Cossarizza A. The immunology of exceptional individuals: the lesson of centenarians. Immunol Today 1995; 16:12-6.

Gabe M, Martoja-Pierson M. Une coloration trichrome en un temps sans diffèrenciation. Bull Micro Appl 1957;7:60-3.

Ganter P, Jollés G. Histochemie normale et pathologique. Vol 1. Gauthier-Villars: Paris; 1970.

Geelhoed GW, Chernow, B. Endocrine aspects of acute illness. Churchill Livingstone: New York; 1985.

Gershon H, Gershon D. Paradigms in aging research: a critical review and assessment. Mech Ageing Dev 2000;117:21-8.

Gershon H, Gershon D. Caenorhabditis elegans - a paradigm for aging research: advantages and limitations. Mech Ageing Dev 2002; 123: 261-74.

Imura H, Fukata JI, Mori T. Cytokines and endocrine function: an interaction between the immune and neuroendocrine systems. Clin Endocrinol 1991;35:107-15.

Kenyon C, Chang J, Gensch E, Rudner A, Tabtiang R. A C. elegans mutant that lives twice as long as wild type. Nature 1993;366:4614.

Kimble J, Sharrock WJ. Tissue-specific synthesis of yolk proteins in Caenorhabditis elegans. Dev Biol 1983;96:189-96.

Kimura KD, Tissenbaum HA, Liu Y, Ruvkun G. daf-2, an insulin receptor-like that regulates longevity and diapause in Caenorhabditis elegans. Science 1997;277:942-6.

Lewis JA, Fleming JT. Basic culture methods. Methods Cell Biol 1995; 48:3-29.

Mori S, Kawano M, Kanzaki T, Morisaki N, Saito Y, Yoshida S. Decreased expression of the platelet-derived growth factor $\beta$-receptor in fibroblasts from a patient with Werner's syndrome. Eur J Clin Invest 1993;23:161-5.

Morris JZ, Tissenbaum HA, Ruvkun G. A phosphatidylinositol-3-OH kinase family member regulating lingevity and diapause in Caenorhabditis elegans. Nature 1996;382:536-9.

Murakami S, Johnson TE. The OLD-1 positive regulator of longevity and stress resistence is under DAF-16 regulation in Caenorhabditis elegans. Curr Biol 2001;11:1517-23.

Ottaviani E, Franceschi F. The invertebrate phagocytic immunocyte: clues to a common evolution of immune and neuroendocrine systems. Immunol Today 1997;18:169-74.

Ottaviani E, Franchini A, Franceschi C. Evidence for the presence of immunoreactive pro-opiomelanocortin-derived peptides and cytokines in the thymus of the goldfish (Carassius $c$. auratus). Histochem J 1995;27:597-601.

Ottaviani E, Franchini A, Franceschi C. Pro-opiomelanocortin-derived peptides, cytokines and nitric oxide in immune responses and stress: an evolutionary approach. Int Rev Cytol 1997;170:79-141.

Ottaviani E, Franchini A, Kletsas D. Platelet-derived growth factor and transforming growth factor- $\beta$ in invertebrate immune and neuroendocrine interactions: another sign of conservation in evolution. Comp Biochem Physiol 2001;129C:295-306.

Riddle DL, Blumenthal T, Meyer BJ, Priess JR. C. elegans II. Cold spring Harbor Laboratory Press: New York; 1997.

White J, Southgate E, Thompson J, Brenner S. The structure of the nervous system of the nematode Caenorhabditis elegans. Phil Trans R S (London) 1986; B314:1-340.

Wolkow CA, Kimura KD, Lee MS, Ruvkun G. Regulation of $C$. elegans life-span by insulinlike signaling in the nervous system. Science 2000;290:147-50.

Wood WB. The Community of C. elegans Researchers: the nematode Caenorhabditis elegans. Cold spring Harbor Laboratory Press; New York: 1988. 